\title{
The effect of strength training based on process approach intervention on balance of children with developmental coordination disorder
}

\author{
Hasan Kordi, PhD Student ${ }^{a}$, Assoc. Prof. Mehdi Sohrabi, Ph.D. ${ }^{a}$, \\ Assist. Prof. Alireza Saberi Kakhki, Ph.D. ${ }^{a}$ and Prof. Seyed R. Attarzadeh Hossini, Ph.D. ${ }^{a}$
}

\begin{abstract}
Introduction. Balance is one of the main problems of children with developmental coordination disorder (DCD). According to process-oriented approach, besides strength training, neuromuscular adaptations can improve balance.
\end{abstract}

Objective. To evaluate the effects of strength training on improving static and dynamic balance in DCD children.

Methods and population. Children between 7 to 9 years old in Tehran participated in the study through randomized controlled trial design. Subjects were randomly divided into two experimental $(n=15)$ and control $(n=$ 15) groups. The participants exercised for 12 weeks and 24 sessions. The experimental group received strength training using flexible Theraband elastic exercise and control group received routine exercises in physical education class. Isometric strength of hip abductor muscles and plantar flexors were measured using hand held dynamometer, and Bruininks-Oseretsky Test of Motor Proficiency, Second Edition (BOT-2) was used for measurement of static and dynamic balance. Data were analyzed using independent and paired sample t-tests.

Results. Strength training significantly increased muscle strength in DCD children $(P<0.001)$ and improved their static balance performance $(\mathrm{P}<0.05)$; however, these exercises had no significant effect on their dynamic balance performance $(\mathrm{P}>0.05)$.

Conclusion. The strength training leads to static balance improve in DCD children. There was not an improvement in dynamic balance through the strength training in these children.

a. Physical education and sport science department, Ferdowsi University of Mashhad, Mashhad, Iran.

E-mail address:

Dr. Mehdi Sohrabi:

sohrabi@um.ac.ir

Funding:

None.

Conflict of interest: None.

Received: 4-7-2016 Accepted: 7-18-2016
Key words: process oriented, resistance training, developmental coordination disorder, postural balance.

http:/ /dx.doi.org/10.5546/aap.2016.eng.526

\section{INTRODUCTION}

Children with developmental coordination disorder (DCD) are those children who do not develop the proper movement patterns coordinated with their age. ${ }^{1}$ Balance and postural control are two major problems in DCD children..$^{2,3}$ The approaches used to treat DCD children can be divided into two main categories: bottom-up and topdown. ${ }^{4}$ Bottom-up approaches (i.e. process-oriented approach) are based on improving underlying deficits and facilitating the growth and neuromaturation, with the assumption that there is direct correlation between underlying processes and functional performance. ${ }^{5}$ The process-oriented approach is based on the assumption that the correct motor function is the result of proper function of neuromuscular system. ${ }^{6,7}$ According to the hypothesis of process-oriented approach, improving body functions such as sensitive integration, kinaesthesia, muscle strength, core stability, visual- motor perception and functions similar to them leads to better performance skills. ${ }^{4,89}$ Therefore, strength training may be considered as a process-oriented intervention method, if it is done with the aim of increasing involved muscle strength. ${ }^{10}$

Extended studies showed the positive effects of strength training programs on enhancement of muscle strength and improvement of balance in children with Down syndrome, ${ }^{11}$ patients suffering from Parkinson's disease, ${ }^{12}$ children with cerebral palsy ${ }^{13}$ and the elderly. ${ }^{14}$ Also some case studies found that strength training improved the muscle strength; gross motor function and proprioception, ${ }^{15}$ motor functions ${ }^{16}$ and performance of gross motor skills ${ }^{17}$ of DCD children. But a series of studies had contradictory results; they reported no significant correlation between postural control and muscle strength and concluded that postural control and muscle strength are independent from each other. ${ }^{18-21}$ 
The treatment of balance problems in DCD children is important. ${ }^{22}$ Furthermore, the conflicting and different views in research findings related to the effect of strength training on balance led to the present study with the objective to evaluate the effects of strength training on improving strength and static and dynamic balance in children with DCD.

\section{POPULATION AND METHODS}

Study design: randomized controlled clinical trial, single-blind, pre and post-test assessment with a reference group.

Randomization was performed by an independient researcher who was not involved in the process of inclusion of subjects. A table of random numbers was used to generate the allocation sequence to the experimental or the control group. Concealed allocation was ensured by using opaque sealed envelopes.

We screened 475 volunteer children, aged 7 to 9 years, from two primary schools in Tehran, Iran. This study was done at indoor gym of their schools between Jan 2016 to Mar 2016. The inclusion criteria were: diagnosis of DCD based on the Diagnostic and Statistical Manual of Mental Disorders- IV ${ }^{1}$ having chronological age of 7 to 9 years, having symptoms of DCD and a normal IQ (above 75). Exclusion criteria were having attention deficit/hyperactivity disorder (ADHD) symptoms, not regularly participating in the training sessions, having severe neurological, musculoskeletal and vision problems as diagnosed by a psychologist and a physician. ${ }^{23}$

Written informed consent was obtained from each participant and parent before the screening and data collection. The minimal effect size for motor training (group training) in improving the motor proficiency of persons with DCD is 0.54 . Therefore, a sample of 29 participants was necessary to achieve a statistical power of 0.8 in pretest and post-test measurements of two DCD groups with the alpha level set at $0.05 .{ }^{3}$ This study was approved by the Research Ethics Committee of Mashhad University of Medical Sciences.

\section{Variables and tools}

Isometric muscle strength of hip abductors and plantar flexor were intended variables for evaluate muscle strength. Static and dynamic balance performances of participants with open and close eyes were variables that evaluated balance proficiency.
Height, weight and body mass index measurement: The height of children were measured 2 times using a wall mounted stadiometer with accuracy of $0.1 \mathrm{~cm}$ and in standing position without shoes. Participants' weights were measured in minimal clothing using Seca digital scale (769G21 model, Germany) with the accuracy of $0.1 \mathrm{~kg}$. Body mass index (BMI) was calculated using the standardized equation (mass/height [in kilograms per square meter]). ${ }^{24}$

Movement Assessment Battery for Children-2 (MABC-2). In this study, Age band 2 (7 to 10 years) was utilized for screening the participant. Typically, children obtaining scores below the 15 percentile meet diagnostic criteria. The MABC-2 test has acceptable validity and reliability. Interrater reliability ranges from 0.92 to 1.00 and the test-retest reliability from 0.62 to $0.92 .{ }^{22}$

Hand-held dynamometer (HHD). To assess the strength of hip abductors and plantar flexor a dynamometer fixed by hand made by J Tech Medical Company (Salt Lake City, US) was used. The assessment was done according to the manual of device (Commande Power Track II). Hand-held dynamometers are frequently used as a valid instrument in various researches for measuring the strength of children's lower limb muscles. ${ }^{16}$

Bruininks-Oseretsky Test of motor proficiency (BOT-2). The BOT-2 covers the age range of 4 to 21 years old. The BOT-2 balance subset includes 9 separate tasks, of which 4 are performed with eyes open, and then eyes closed. The BOT-2 test has a sufficient test-retest reliability of 0.85 and inter-rater reliability of 0.98 . There is also strong support for adequate construct validity. ${ }^{22}$

\section{Interventions}

The participants attended two 60 min session of strength training (experimental group) or ordinary physical education (control group) held at their physical education (PE) class per week for 12 consecutive weeks ( 24 sessions). The regular PE teacher and a Certified Strength and Conditioning Specialist who had experience in training with children provided instruction every class. Participants in control group did not perform strength training but attended their regular PE class twice per week (Sunday and Tuesday) during the study period in a different class by the same time that experimental group. All measurements were made by two persons who are expert in muscle strength testing and procedure of BOT-2 and MABC-2. 
The strength training program was designed based on the method recommended by American Academy of Pediatrics which is a moderate load training program..$^{24}$ The strength training protocol emphasized strengthening the core muscles and lower limb muscles involved in static and dynamic balance included: leg abductors and adductors, knee flexor and extensors, abdominals, back extensors and plantar flexors. ${ }^{17,25}$ Strength training program in which Thera-Band ${ }^{\circledR}$ elastic bands were used with the consideration of body weight in supine or prone positions ${ }^{17}$ was chosen and programs including free weight training and weight machines were not applied (Figure 1).

FIGURE 1. Plan of strength training. a: Supine position unilateral hip adduction; $b$ : Side-lying hip abduction; c: Seated unilateral knee extension; d: Standing position unilateral knee flexion; e: Standing bilateral heel raises; $f$ : Supine position bridging

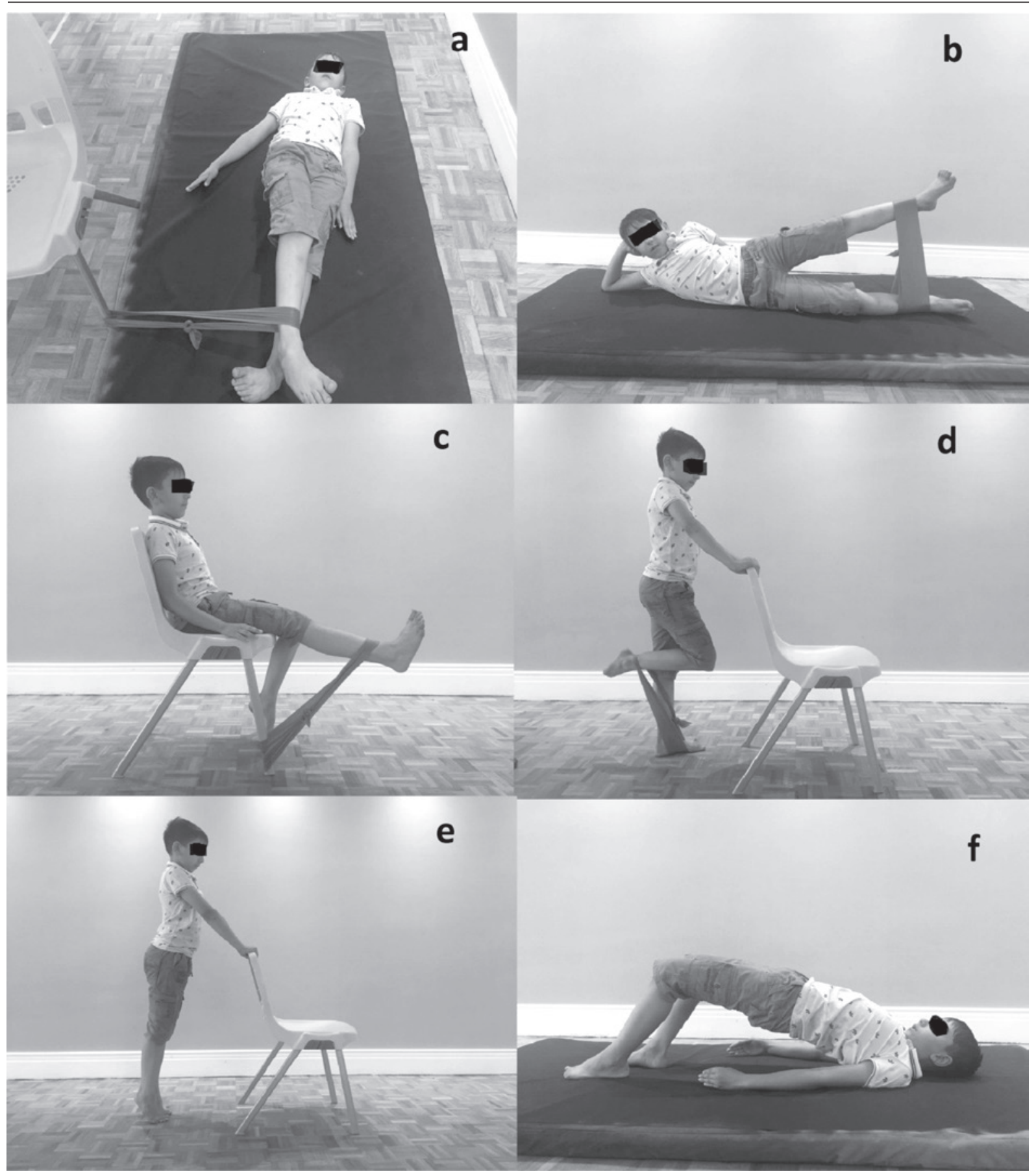


Table 1 outlines the structure and content of the strength training program. Participants performed 2 sets with 10 repetitions on all primary exercises first week and during the 12 week training period they progressed from 2 to 3 sets and from 10 to 15 repetitions on the exercise.

\section{Statistical analysis}

The collected data were analyzed through descriptive statistic (mean and standard deviation), ensuring data normal distribution by Shapiro Wilk test and then independent and paired sample t-test with $(\alpha=0.05)$ as well as SPSS software version 18.

\section{RESULTS}

We screened 475 volunteer children, aged 7 to 9 years; 56 children had symptoms of DCD; 4 of these children based of their parents' opinions (their disagreement to participate) and 22 children due to having ADHD symptoms were excluded. The rest was distributed randomly in two groups of 15 children every one (experimental and control groups) and participated till the end of the study.

Descriptive information about the distribution of gender, age, height, weight and BMI of the participants in the study are presented in Table 2. The mean and standard deviation scores in variables of muscle strength and motor skills at pre-test and post-test of the two groups showed in Table 3.

The results of Shapiro Wilk test indicated the normal distribution of balance and muscle strength variables in two groups $(p>0.05)$. Independent sample t-test between the two groups in pre-test showed that there was no significant difference in isometric muscle strength and balance variables $(\mathrm{P}<0.05)$. The comparison between the mean scores of pre-test and post-test muscle strength with paired sample t-test showed that strength training program significantly increased isometric strength of hip and dorsiflexor muscles (Table 3).

TABLE 1. Strength training schedule's of experimental group

\begin{tabular}{lcccccccccccc}
\hline Exercise & Week 1 & Week 2 & Week 3 & Week 4 & Week 5 & Week 6 & Week 7 & Week 8 & Week 9 & Week 10 & Week 11 & Week 12 \\
\hline $1^{+}$ & $2^{*} 10$ & $3^{*} 10$ & $3^{*} 10$ & $3^{*} 12$ & $3^{*} 12$ & $3^{*} 10$ & $3^{*} 15$ & $3^{*} 15$ & $3^{*} 12$ & $3^{*} 15$ & $3^{*} 15$ & $3^{*} 15$ \\
2 & $2^{*} 10$ & $3^{*} 10$ & $3^{*} 10$ & $3^{*} 12$ & $3^{*} 12$ & $3^{*} 10$ & $3^{*} 15$ & $3^{*} 15$ & $3^{*} 12$ & $3^{*} 15$ & $3^{*} 15$ & $3^{*} 15$ \\
3 & $2^{*} 10$ & $3^{*} 10$ & $3^{*} 10$ & $3^{*} 12$ & $3^{*} 12$ & $3^{*} 10$ & $3^{*} 15$ & $3^{*} 15$ & $3^{*} 12$ & $3^{*} 15$ & $3^{*} 15$ & $3^{*} 15$ \\
4 & $2^{*} 10$ & $3^{*} 10$ & $3^{*} 10$ & $3^{*} 12$ & $3^{*} 12$ & $3^{*} 10$ & $3^{*} 15$ & $3^{*} 15$ & $3^{*} 12$ & $3^{*} 15$ & $3^{*} 15$ & $3^{*} 15$ \\
5 & $2^{*} 10$ & $3^{*} 10$ & $3^{*} 10$ & $3^{*} 12$ & $3^{*} 12$ & $3^{*} 10$ & $3^{*} 15$ & $3^{*} 15$ & $3^{*} 12$ & $3^{*} 15$ & $3^{*} 15$ & $3^{*} 15$ \\
6 & $2^{*} 10$ & $3^{*} 10$ & $3^{*} 10$ & $3^{*} 12$ & $3^{*} 12$ & $3^{*} 10$ & $3^{*} 15$ & $3^{*} 15$ & $3^{*} 12$ & $3^{*} 15$ & $3^{*} 15$ & $3^{*} 15$ \\
\hline
\end{tabular}

† Type of exercise according to; 1: Supine position unilateral hip adduction; 2: Side-lying hip abduction;

3: Seated unilateral knee extension; 4: Standing position unilateral knee flexion; 5 : Standing bilateral heel raises;

6: Supine position bridging.

TABLE 2. Descriptive information's of participants in this study

\begin{tabular}{lccccccc}
\hline Group & $\mathbf{N}$ & Boy & Girl & Weight $(\mathbf{k g})$ & Height $(\mathbf{c m})$ & Age (years) & BMI $\left(\mathbf{k g} / \mathbf{m}^{2}\right)$ \\
\hline Experimental & 15 & 10 & 5 & $26.33 \pm 3.51$ & $120.93 \pm 2.78$ & $8.01 \pm 0.54$ & $26.33 \pm 3.51$ \\
Control & 15 & 12 & 3 & $25.00 \pm 2.26$ & $119.60 \pm 3.135$ & $7.70 \pm 0.63$ & $25.00 \pm 2.26$ \\
\hline
\end{tabular}

TABLE 3. Paired sample t test for compare the pre to post-test isometric muscle strength

\begin{tabular}{|c|c|c|c|c|c|c|c|}
\hline & Group & $\begin{array}{c}\text { Pre test } \\
\text { Mean (SD) }\end{array}$ & $\begin{array}{c}\text { Post test } \\
\text { Mean (SD) }\end{array}$ & $\mathbf{t}$ & $\mathbf{P}$ & df & $\begin{array}{c}\text { Std. Error } \\
\text { Mean }\end{array}$ \\
\hline \multirow[t]{2}{*}{ Hip abduction } & Experimental & $7.15 \pm 1.23$ & $9.86 \pm 1.28$ & -8.703 & $0.0001^{*}$ & 14 & 0.31033 \\
\hline & Control & $7.51 \pm 1.16$ & $7.45 \pm 1.21$ & 0.460 & 0.653 & 14 & 0.13918 \\
\hline \multirow[t]{2}{*}{ Dorsi flextion } & Experimental & $8.62 \pm 1.16$ & $10.95 \pm 1.34$ & -8.081 & $0.0001^{*}$ & 14 & 0.28881 \\
\hline & Control & $7.98 \pm 1.01$ & $7.81 \pm 0.66$ & 0.956 & 0.355 & 14 & 0.18474 \\
\hline
\end{tabular}

$*(\mathrm{p}<0.05)$ 
In order to see the effect of strength training on static and dynamic balance, the mean scores of pre-test and post-test were compared by paired sample t-test (Table 4). The results showed that resistance training significantly increased the performance of DCD children in standing on a line, standing on one leg on a line, standing with feet apart on a line (eyes close), standing on one leg on a balance beam and standing heel-totoe on a balance beam but this exercise had no significant effect on dynamic balance items.

The results of independent sample t-test in post-test showed significant differences between the two groups in standing on a line $(t=2.054, \mathrm{p}=$ $0.049)$, standing on one leg on a line $(t=2.442, p=$ $0.021)$, standing on one leg on a balance beam ( $\mathrm{t}=$ $3.848, \mathrm{p}=0.001)$.

\section{DISCUSSION}

The present study aimed to determine the effect of strength training on improving static and dynamic balance in children with DCD. The results showed that strength training program can increase muscle strength in DCD children. This finding was consistent with some previous researches on $\mathrm{DCD}^{15,16}$ but was not consistent with reports of Menz et al. ${ }^{17}$ However, the child under study in the work of Menz et al., ${ }^{17}$ was a 7-year-old girl who had apraxia, hypotonia and motor delay symptoms besides developmental coordination disorder. In addition, her training program was conducted with the use of machine weights strength training. So it can be said that the difference in the level and severity of disorders of subjects in these two studies and different models used in them are the main reasons of inconsistencies between present study and the one carried out by Menz et al. ${ }^{17}$ Strength development consists of the coordinated function of neural, muscular and metabolic systems. The adaptations occurred as the result of strength training and led to an increase in maximum strength including neural adaptations such as increasing motor unit recruitment, involving motor units in agonist muscles, more frequent stimulation of motor units, autogenic inhibition by Golgi tendon, increasing neuromuscular cooperation and muscular adaptations such as increased muscle crosssectional area and changes in muscle structure. ${ }^{26,27}$ In the early stages of strength training in children, the dominant mechanisms for increasing strength are neural adaptations. ${ }^{28}$ Therefore it is possible that some specific neural adaptations which occur in muscle due to increasing inter and intra muscular coordination have led to increased strength in the subjects of the study. ${ }^{29}$

TABLE 4. Compare mean of scores between pre to post-test in static and dynamic balance

\begin{tabular}{|c|c|c|c|c|c|c|c|}
\hline & group & $\begin{array}{c}\text { Pre test } \\
\text { Mean (SD) }\end{array}$ & $\begin{array}{l}\text { Post test } \\
\text { Mean (SD) }\end{array}$ & $\mathbf{t}$ & $\mathbf{P}$ & df & $\begin{array}{l}\text { Std. Error } \\
\text { Mean }\end{array}$ \\
\hline Standing on a line & $\begin{array}{l}\text { Experimental } \\
\text { control }\end{array}$ & $\begin{array}{l}4.13 \pm 0.83 \\
4.01 \pm 1.00\end{array}$ & $\begin{array}{l}4.80 \pm 0.86 \\
4.13 \pm 0.91\end{array}$ & $\begin{array}{l}-3.568 \\
-0.619\end{array}$ & $\begin{array}{l}0.003^{*} \\
0.546\end{array}$ & $\begin{array}{l}14 \\
14\end{array}$ & $\begin{array}{l}0.187 \\
0.215\end{array}$ \\
\hline $\begin{array}{l}\text { Walking forward } \\
\text { on a line }\end{array}$ & $\begin{array}{l}\text { Experimental } \\
\text { control }\end{array}$ & $\begin{array}{l}3.73 \pm 0.96 \\
4.20 \pm 1.01\end{array}$ & $\begin{array}{l}4.00 \pm 1.13 \\
3.93 \pm 0.70\end{array}$ & $\begin{array}{l}-0.845 \\
1.169\end{array}$ & $\begin{array}{l}0.413 \\
0.262\end{array}$ & $\begin{array}{l}14 \\
14\end{array}$ & $\begin{array}{l}0.316 \\
0.228\end{array}$ \\
\hline $\begin{array}{l}\text { Standing on one leg } \\
\text { on a line }\end{array}$ & $\begin{array}{l}\text { Experimental } \\
\text { control }\end{array}$ & $\begin{array}{l}2.93 \pm 0.96 \\
3.47 \pm 1.12\end{array}$ & $\begin{array}{l}4.40 \pm 0.83 \\
3.67 \pm 0.82\end{array}$ & $\begin{array}{l}-7.643 \\
-1.382\end{array}$ & $\begin{array}{c}0.0001^{*} \\
0.189\end{array}$ & $\begin{array}{l}14 \\
14\end{array}$ & $\begin{array}{l}0.192 \\
0.145\end{array}$ \\
\hline $\begin{array}{l}\text { Standing with feet apart } \\
\text { on a line (eyes close) }\end{array}$ & $\begin{array}{l}\text { Experimental } \\
\text { control }\end{array}$ & $\begin{array}{l}3.07 \pm 0.79 \\
2.93 \pm 0.59\end{array}$ & $\begin{array}{l}3.67 \pm 0.82 \\
3.33 \pm 0.72\end{array}$ & $\begin{array}{l}-2.201 \\
-1.572\end{array}$ & $\begin{array}{c}0.045^{*} \\
0.138\end{array}$ & $\begin{array}{l}14 \\
14\end{array}$ & $\begin{array}{l}0.273 \\
0.254\end{array}$ \\
\hline $\begin{array}{l}\text { Walking forward on } \\
\text { a line (heel to toe) }\end{array}$ & $\begin{array}{l}\text { Experimental } \\
\text { control }\end{array}$ & $\begin{array}{l}3.00 \pm 0.75 \\
3.40 \pm 0.73\end{array}$ & $\begin{array}{l}2.93 \pm 0.59 \\
3.00 \pm 0.65\end{array}$ & $\begin{array}{l}0.367 \\
1.702\end{array}$ & $\begin{array}{l}0.719 \\
0.111\end{array}$ & $\begin{array}{l}14 \\
14\end{array}$ & $\begin{array}{l}0.182 \\
0.235\end{array}$ \\
\hline $\begin{array}{l}\text { Standing on one leg } \\
\text { on a line (eyes close) }\end{array}$ & $\begin{array}{l}\text { Experimental } \\
\text { control }\end{array}$ & $\begin{array}{l}2.07 \pm 0.79 \\
1.87 \pm 0.64\end{array}$ & $\begin{array}{l}2.13 \pm 0.64 \\
2.00 \pm 0.53\end{array}$ & $\begin{array}{l}-0.564 \\
-1.468\end{array}$ & $\begin{array}{l}0.582 \\
0.164\end{array}$ & $\begin{array}{l}14 \\
14\end{array}$ & $\begin{array}{l}0.118 \\
0.091\end{array}$ \\
\hline $\begin{array}{l}\text { Standing on one leg } \\
\text { on a balance beam }\end{array}$ & $\begin{array}{l}\text { Experimental } \\
\text { control }\end{array}$ & $\begin{array}{l}2.73 \pm 0.70 \\
2.60 \pm 0.83\end{array}$ & $\begin{array}{l}3.87 \pm 0.74 \\
2.80 \pm 0.77\end{array}$ & $\begin{array}{l}-4.141 \\
-1.871\end{array}$ & $\begin{array}{l}0.001^{*} \\
0.082\end{array}$ & $\begin{array}{l}14 \\
14\end{array}$ & $\begin{array}{l}0.274 \\
0.107\end{array}$ \\
\hline $\begin{array}{l}\text { Standing heel-to-toe } \\
\text { on a balance beam }\end{array}$ & $\begin{array}{l}\text { Experimental } \\
\text { control }\end{array}$ & $\begin{array}{l}2.87 \pm 0.64 \\
3.20 \pm 0.67\end{array}$ & $\begin{array}{l}3.20 \pm 0.67 \\
3.27 \pm 0.59\end{array}$ & $\begin{array}{l}-2.646 \\
-1.000\end{array}$ & $\begin{array}{c}0.019^{*} \\
0.334\end{array}$ & $\begin{array}{l}14 \\
14\end{array}$ & $\begin{array}{l}0.126 \\
0.067\end{array}$ \\
\hline $\begin{array}{l}\text { Standing on one leg on a } \\
\text { balance beam (eyes close) }\end{array}$ & $\begin{array}{l}\text { Experimental } \\
\text { control }\end{array}$ & $\begin{array}{l}1.67 \pm 0.62 \\
2.07 \pm 0.79\end{array}$ & $\begin{array}{l}1.73 \pm 0.45 \\
2.13 \pm 0.64\end{array}$ & $\begin{array}{l}-0.435 \\
-0.367\end{array}$ & $\begin{array}{l}0.670 \\
0.719\end{array}$ & $\begin{array}{l}14 \\
14\end{array}$ & $\begin{array}{l}0.153 \\
0.182\end{array}$ \\
\hline
\end{tabular}

$*(\mathrm{p}<0.05)$ 
Another part of the results showed that strength training has led to significant improvements in static balance of DCD children. These findings were consistent with those of Kaufman and Schilling, ${ }^{15}$ Kane and Bell ${ }^{16}$ and Menz et al., ${ }^{17}$ but not consistent with results of Granacher and Gollhofer, ${ }^{18}$ Granacher et al., ${ }^{19}$ and McCurdy and Langford. ${ }^{21}$ The difference in results may be due to difference in the participants, training programs and balance measurement method. Although the somatosensory and vestibular systems play an important role in balance control, ${ }^{30}$ good postural control depends on musculoskeletal biomechanics system (stability and structure of the joint) as well as proper neuromuscular control. In fact, muscles through the joints control the balance and muscles in the trunk, hip, knee and ankle play an essential role in regulating the balance. ${ }^{31}$ Enoka ${ }^{32}$ believes that the increase in muscle strength through training can be the result of changes in the neural mechanisms including increased output of supraspinal centers, changes in neural pathways that reduce the activity of antagonist muscles, increasing the activity of agonist muscles or effective communication via inter-neuronal pathways. Specific neural adaptations that occur in the muscles as the result of strength training are due to increased intra-muscular coordination, inter-muscular coordination, or both. Intramuscular neural adaptations include the activation of motor units, firing frequency, synchronization of motor unit firing, stretch reflex and inter-muscular adaptations are activation of corresponding (synergist) muscles and co-contraction of antagonist muscles. ${ }^{33}$ So, one can conclude that neuromuscular adaptations and improvement of muscles and joints sensory functions occurred as the result strength trainings and led to improved static balance in the DCD children under study. The results showed that strength training had no significant effect on dynamic balance in children with DCD. The results were consistent with findings of Bohannon ${ }^{20}$ on patients referred to physiotherapy, Granacher and Gollhofer ${ }^{18}$ and Granacher et al., ${ }^{19}$ on prepubertal children but were not consistent with results of Kaufman and Schilling, ${ }_{1}^{15}$ Kane and Bell ${ }^{16}$ Menz et al., ${ }^{17}$ on children with motor deficit. It can be said that, this inconsistencies are due to different research and balance assessment methods and difference in level and severity of subjects' disorder. Based on Granacher and Gollhofer ${ }^{18}$ findings, it can be hypothesized that different neuromuscular mechanisms are responsible for the regulation of static and dynamic postural control. Thus, it could be reasoned out that static posture was regulated and controlled by visual and proprioceptive information, whereas dynamic posture was primarily organized by visual information. Previous research showed that no significant associations were found between variables of postural control and muscle strength in children ${ }^{18,19}$ and older adults. ${ }^{21}$ Granacher and Gollhofer ${ }^{18}$ were not able to detect significant correlations between static and dynamic balance control perturbation and isometric and dynamic muscle actions. Based on our results and the findings reported in the literature for different age groups and testing methodologies, ${ }^{19,21}$ it seems plausible to argue that postural control and muscle strength are independent of each other ${ }^{18}$ and this is contrary to the assumption of process oriented approach.

The process of balance is based on two factors, good sense and muscle function. Strengthening muscles can improve their function; in fact, balance is the result of interaction of sensory components such as vestibular, visual and proprioception systems which coordinates the contractions of leg muscles. ${ }^{34}$ According to Dynamic Systems Theory which recently has become the basis of researches on movement and balance, the ability to control body position and balance in the space is the result of a complex interaction among different muscular, skeletal and neural systems and the importance of each system is different according to its purpose of movement and circumstances. ${ }^{21}$ In this model, the central nervous system using data received from visual, vestibular and somatosensory systems becomes aware of body's center of gravity and supporting surface and activate preprogrammed motor patterns as motor responses. ${ }^{35}$ To justify this, one can say that since one of the tasks of the vestibular system is resolving sensory conflicts and this system has a poor function in DCD children, ${ }^{3}$ the dynamic balance task in these children hasn't been improved by mere strength training and increasing the muscle strength. Therefore regarding the type of task and function of systems involved in it, the result confirms the dynamic system theory. Lack of recorded data on neuromuscular changes and function of other parts involved in keeping balance such as vestibular system and cerebellum, as well as small size of sample are some of limitations of the 
study, so generalization of the results of this study should be done with caution.

\section{CONCLUSIONS}

The strength training leads to static balance improve in DCD children. There was not an improvement in dynamic balance through the strength training in these children.

\section{Acknowledgement}

We wish to thank all children who participated in this study. Special thanks to Dr. Mohsen Damavandi, Dr. Bouwien C.M. Smits-Engelsman, Fahime Zoghi and Dorothee Jelsma for their contribution and technical support.

\section{REFERENCES}

1. American Psychiatric Association. Diagnostic and Statistical Manual of Mental Disorders. 5th ed. Washington, DC; American Psychiatric Association: 2013.

2. Deconinck FJ, Savelsbergh GJ, De Clercq D, Lenoir M. Balance problems during obstacle crossing in children with Developmental Coordination Disorder. Gait Posture 2010;32(3):327-31.

3. Fong SS, Tsang WW, NgGY. Taekwondo training improves sensory organization and balance control in children with developmental coordination disorder: a randomized controlled trial. Res Dev Disabil 2012;33(1):85-95.

4. Sugden D. Current approaches to intervention in children with developmental coordination disorder. Dev Med Child Neurol 2007;49(6):467-71.

5. Chen HF, Tickle-Deghnan L, Cermak CA. The treatment effectiveness of top-down approaches for children with developmental coordination disorder: A meta-analysis. $J$ Occupat Therapy Assoc 2003;21:16-28.

6. Mandich AD, PolatajkoHJ, MacnabJJ, Miller LT. Treatment of children with Developmental Coordination Disorder: what is the evidence? Phys Occup Ther Pediatr 2001;20(23):51-68.

7. MathiowetzV, Bass HaugenJ.Evaluation of Motor Behavior: traditional and contemporary views. In: Trombly CA, ed. Occupational therapy for physical dysfunction. $4^{\text {th }} \mathrm{ed}$. Boston: Lippincott Williams \& Wilkins; 1995.Págs.157-85.

8. Barnhart RC, Davenport MJ, Epps SB, et al. Developmental coordination disorder. Phys Ther 2003; 83(8):722-31.

9. Polatajko HJ, Kaplan BJ, Wilson BN. Sensory integration treatment for children with learning disabilities: Its status 20 years later. Occupat Therapy J Res 1992;12(6):323-41.

10. Smits-Engelsman BC, Blank R, van der Kaay AC, Mosterdvan der Meijs R, et al. Efficacy of interventions to improve motor performance in children with developmental coordination disorder: a combined systematic review and meta-analysis. Dev Med Child Neurol 2013;55(3):229-37.

11. Kubilay NS, Yildırım Y, Kara B, Haruto lu Akdur H. Effect of balance training and posture exercises on functional level in mental retardation. Fizyoter Rehabil 2011;22(2):55-64.

12. Dibble LE, Hale TF, Marcus RL, Droge J, etal. High-intensity resistance training amplifies muscle hypertrophy and functional gains in persons with Parkinson's disease. Mov Disord 2006;21(9):1444-52.

13. Scholtes VA, Becher JG, Comuth A, Dekkers H, et al. Effectiveness of functional progressive resistance exercise strength training on musclestrength and mobility in children with cerebral palsy: a randomized controlled trial. Dev Med Child Neurol 2010;52(6):e107-13.
15. Kaufman LB, Schilling DL. Implementation of a strength training program for a 5-year-old child with poor body awareness and developmental coordination disorder. Phys Ther 2007;87(4):455-67.

16. Kane K, Bell. A core stability group program for children with developmental coordination disorder: 3 clinical case reports. Pediatr Phys Ther 2009;21(4):375-82.

17. Menz SM, Hatten K, Grant-Beuttler M. Strength training for a child with suspected developmental coordination disorder. Pediatr Phys Ther 2013;25(2):214-23.

18. Granacher U, Gollhofer A. Is there an association between variables of postural control and strength in prepubertal children? J Strength Cond Res 2012;26(1):210-6.

19. Granacher U, Muehlbauer T, Maestrini L, Zahner L, et al. Can balance training promote balance and strength in prepubertalchildren? J Strength Cond Res 2011;25(6):1759-66.

20. Bohannon RW. Standing balance, lower extremity muscle strength, and walking performance of patients referred for physical therapy. Percept Mot Skills 1995;80(2): 379-85.

21. McCurdy K, Langford G. The relationship between maximum unilateral squat strength and balance in young adult men and women. J Sports Sci Med 2006;5(2):282-8.

22. Mombarg R, Jelsma D, Hartman E. Effect of Wii-intervention on balance of children with poor motor performance. Res Dev Disabil 2013;34(9):2996-3003.

23. ZwickerJG,Missiuna C,Harris SR, BoydLA. Brain activation of children with developmental coordination disorder is different than peers. Pediatrics 2010;126(3):e678-86.

24. Faigenbaum A, MyerGD. Resistance training among young athletes: safety, efficacy and injury prevention effects. $\mathrm{Br} J$ Sports Med 2010;44(1):56-63.

25. GuptaS, RaoBK,KumaranSD. Effect of strength and balance training in children with Down's syndrome: a randomized controlled trial. Clin Rehabil 2011;25(5):425-32.

26. Kraemer WJ, Adams K, Cafarelli E, Dudley GA, et al. American College of Sports Medicine position stand. Progression models in resistance training for healthy adults. Med Sci Sports Exerc 2002;34(2):364-80.

27. Hakkinen K, Alen M, Kaninen M, Newton RU, et al. Neuromuscular adaptation during prolonged strength training, detraining and restrength-training in middle-aged and elderly people. Eur J Appl Physiol 2000;83(1):51-62.

28. Ebersole KT, Housh TJ, Johnson GO, Perry SR, et al. Mechanomyographic and electromyographic responses to unilateral isometric training. J Strength Cond Res 2002;16(2):192-201.

29. Aagaard P, Andersen JL, Dyhre-Poulsen P, Leffers et al. A mechanism for increased contractile strength of human pennate muscle in response to strength training: changes in muscle architecture. J Physiol 2001;534 (Pt 2):613-23.

30. Qiu F, Cole MH, Davids KW, Hennig EM, et al. Enhanced somatosensory information decreases postural sway in older people. Gait Posture 2012;35(4):630-5.

31. Alaranta H, Moffroid M, Elmqvist LG, Held J, et al. Postural control of adults with musculoskeletal impairment. Crit Rev Phys Rehabil Med 1994;6(4):337-79.

32. Enoka RM. Neural strategies in the control of muscle force. Muscle Nerve Suppl 1997;5:66-69.

33. Hammett JB, Hey WT. Neuromuscular adaptation to shortterm (4weeks) ballistic training in trained higth school athletes. J Strength Cond Res 2003;17(3):556-60.

34. Butler AA, Lord SR, Rogers MW, Fitzpatrick RC. Muscle weakness impairs the proprioceptive control of human standing. Brain Res 2008;1242:244-51.

35. Shumway-CookA, WoollacottMH. Motor control: theory and practical applications. Baltimore: Williams \& Wilkins; 1995. 